\title{
A poetisa do Jardim de Infância: contribuições de Zalina Rolim para consolidação da poesia infantil
}

\author{
Cristina Loff Knapp ${ }^{\mathrm{i}}$
}

\begin{abstract}
RESUMO
O presente artigo tem o objetivo de investigar a notoriedade da poetisa Zalina Rolim para a literatura infantil brasileira no século XIX. Para tanto, nosso corpus de estudo serão os poemas publicados pela autora na revista $A$ Mensageira, com a intenção de trazer à tona as vozes não consagradas pela historiografia literária tradicional. Além disso, faremos uma breve comparação com poemas publicados em seu primeiro livro dedicado aos pequenos: O Livro das Crianças (1897). Assim, queremos demonstrar a riqueza de seus poemas para a literatura infantil brasileira. Nossa discussão terá como baliza norteadora os Estudos Culturais de Gênero e o resgate da escrita das mulheres na imprensa.
\end{abstract}

Palavras-chave: Zalina Rolim; poesia infantil; resgate de escritoras; estudos culturais de gênero.

\begin{abstract}
This article aims to investigate the notoriety of the poet Zalina Rolim for Brazilian children's literature in the 19th century. For this purpose, our corpus of study will be the poems published by the author in the magazine A Mensageira, with the intention of bringing to light the voices not consecrated by traditional literary historiography. In addition, we will make a brief comparison with poems published in his first book dedicated to the little ones: The Children's Book (1897). Thus, the richness of his poems for Brazilian children's literature will be demonstrated. Our discussion will be guided by Cultural Studies of Gender and the rescue of women's writing in the press.
\end{abstract}

Keywords: Zalina Rolim; children's poetry; Rescue of female writers; Cultural studies of gender.

\section{INTRODUÇÃO}

i Doutora em Literatura Comparada pela Universidade Federal do Rio Grande do Sul (UFRGS). Mestra em Literatura Brasileira pela Universidade Federal do Rio Grande do Sul (UFRGS). Possui Graduação em Letras- Português pela Universidade do Vale do Rio dos Sinos (UNISINOS). Professora no Curso de Letras da Universidade de Caxias do Sul. Atua como pesquisadora voluntária no projeto Representações do Insólito na Literatura de Autoria Feminina (INSÓLITO) coordenado pela profa. Dra. Cecil Jeanine Albert Zinani. ORCID: https://orcid.org/0000-0002-1593-8734 / crislknapp@gmail.com 
Os livros destinados às crianças e jovens teriam surgido, no Brasil, no século XVIII e, geralmente, estiveram relacionados ao ambiente escolar. Marisa Lajolo e Regina Zilberman (1995) elucidam que a literatura infantil não obteve êxito de divulgação em seus primeiros escritos. Somente com o processo de industrialização das cidades que esse quadro foi mudando, visto que o livro infantil passou a ser associado à escola.

Contudo, essa relação com a educação e com o ensinar fez com que muitos críticos considerassem a literatura infantil como um gênero menor. Nas palavras de Renato Almeida (2003):

[...] literatura infantil brasileira desde logo nos surpreende o número ainda reduzido de especialistas no gênero. A maioria dos autores se compõe de escritores que também escrevem para crianças não raro acidentalmente. Outros são improvisadores. Poucos possuem técnica e orientação, nem sempre supridas por pendor legítimo. Resultam livros, às vezes de valor artístico, bem urdidos e bem encaminhados, mas falhos na intenção, na forma, no critério, na originalidade sobretudo (ALMEIDA, 2003, p. 220221).

Dessa forma, torna-se relevante investigar a produção literária infantil da poetisa Zalina Rolim, seus poemas na obra $O$ Livro das crianças e os seus escritos na revista $A$ Mensageira. Escritos de qualidade, diante das inúmeras produções "improvisadoras", supracitando Almeida. O gênero, como informa Nelly Novaes Coelho (2000, p. 30), só atingiu o reconhecimento um pouco tardiamente, e é um "fenômeno significativo na formação das mentes infantis e juvenis". Assim, faremos um breve percurso pela história da literatura infantil brasileira a fim de validar como os poemas de Zalina Rolim, publicados tanto na obra $O$ livro das crianças (1897) como na revista $A$ Mensageira não podem ficar no esquecimento.

\section{A LITERATURA INFANTIL}

A literatura infantil teve suas primeiras publicações no século XVII, mais especificamente em 1697, com Charles Perrault, com a obra Contos da Mamãe Gansa. Foram contos de fadas. Todavia, sabe-se que anterior a essa publicação, figuraram histórias, lendas que podem também ser consideradas como literatura para crianças, na 
cultura erudita e manifestando-se, também, na cultura popular, como elucida Lígia Cademartori (1987). Coelho (2012) aponta para fontes orientais, a coletânea Calila $e$ Dimna, como sendo uma das primeiras publicações infantis.

Já Zilberman (2003) afirma que a ideia que se tem de criança hoje difere muito dos séculos anteriores. Não se escreveu para as crianças, por isso, não existiu uma literatura destinada a esse público. Os pequenos foram vistos como adultos em miniatura e participavam de tudo na vida adulta, inclusive suas vestimentas eram parecidas com as dos mais velhos.

No entanto, no chamado Estado Moderno, segundo Zilberman (2003), houve a organização da sociedade burguesa e a família passou a ser o centro de tudo, estimulando-se o afeto entre os cônjuges e entre pais e filhos. Na classe burguesa a tarefa de educar compete à mãe, o mesmo não ocorre com as crianças proletárias que foram vistas como mão de obra barata e foram inseridas no mercado de trabalho muito cedo.

Assim, a instituição escola passou a ter um papel de relevo, uma vez que mantinha a criança longe do mercado de trabalho adulto. A literatura infantil ganhou destaque nesse período, porém relacionada à ideia pedagógica. No Brasil, o fenômeno é o mesmo.

A Instituição escola fez crescer a literatura infantil e o seu caráter pedagógico. $\mathrm{O}$ livro infantil passou a fazer parte do dia a dia da criança na escola. Os livros didáticos surgiram com inúmeros trechos de poemas, contos, enfim adquiriram o papel de divulgação da literatura infantil. Para Coelho (2000):

\footnotetext{
Literatura é uma linguagem específica que, como toda linguagem expressa uma determinada experiência humana, e dificilmente poderá ser definida com exatidão. Cada época compreendeu e produziu literatura a seu modo [...]. Conhecer a literatura que cada época destinou às suas crianças é conhecer os ideais e valores ou desvalores sobre os quais cada sociedade se fundamentou (e se fundamenta...) (COELHO, 2000, p. 27-28).
}

A longa citação de Coelho elucida que a literatura infantil procurou adequar-se ao seu tempo. Esse, de certa forma, é o percurso da literatura infantil. Se a pensarmos atualmente, no Brasil, inúmeras serão as diferenças daquelas produções do início do século XX, por exemplo. 
É justamente assim, que se enfatiza a importância que a literatura voltada para crianças carrega consigo. No final do século XVIII, início do século XIX, as produções trouxeram à tona o ensino, e conforme Coelho (2010) a cidade de São Paulo foi o centro de renovação educacional no período. Assim, publicações voltadas aos pequenos começaram a ser adotadas nas escolas, junto com as cartilhas. Nas palavras de Coelho (2010, p. 206) “a primeira manifestação consciente da produção de uma leitura específica para crianças", como também "a primeira tentativa de realização de uma literatura para crianças".

É nesse período que ganhou saliência a poetisa Zalina Rolim, objeto de nosso estudo. Sua obra Livro das crianças (1897) reuniu poemas, contos e historietas em verso. A publicação ficou a cargo do Governo de São Paulo e o livro foi distribuído nas escolas, como nos informa Coelho (2010). Também é procedente ressaltar a participação de Rolim no movimento feminista e os seus inúmeros projetos de inovação para o ensino básico de São Paulo. A autora também contribuiu na revista $A$ Mensageira. Isso nos mostra o quão importante Rolim foi, não somente para a literatura infantil brasileira, mas também para a consolidação das ideias de Fröebel, na educação infantil.

\section{A REVISTA A MENSAGEIRA E A CONSOLIDAÇÃO DA ESCRITA FEMININA}

A revista $A$ Mensageira merece destaque entre as publicações da imprensa feminina no século XIX, foi publicada na década de 80, mais precisamente em 1987, uma edição fac-similar pela Secretaria do Estado da Cultura e Imprensa Oficial do Estado de São Paulo. Foi uma revista destinada à mulher brasileira. Presciliana Duarte de Almeida foi sua editora, e circulou entre os anos de 1897 e 1900, divulgando escritos literários e foi também o local de ecoar vozes silenciadas e oprimidas.

Carlos Costa (2012, p. 404) pondera que a importância da revista estava justamente no fato de defender os direitos das mulheres, assim como o voto, todavia, não deixando no esquecimento o papel de mãe e esposa. Sylvia Paixão (1989) em suas argumentações vai ao encontro do que afirma Costa sobre A Mensageira: 
era através deste veículo que fazia circular as suas confidências, os seus segredos e também o seu ideário, expresso nos contos e crônicas ali publicados. Embora propondo a educação da mulher, promovendo a leitura e incitando a sua profissionalização, a ideologia contida na revista ainda reproduzia o preconceito e a repressão dirigidos a ela, no sentido de impedir o seu ingresso na esfera pública (PAIXÃO, 1989, p. 54).

O primeiro número da revista circulou no dia 15 de outubro do ano de 1897 e sua edição foi de quinze em quinze dias. Ainda sobre o primeiro número, transcrevemos a intenção da revista, na coluna Duas Palavras, assinada por Presciliana Duarte de Almeida:

Estabelecer entre as brazileiras uma sympathia espiritual, pela comunhão das mesmas idéias, levando-lhes de quinze em quinze dias, ao remansoso lar, algum pensamento novo - sonho de poeta ou fructo de observação acurada, eis o fim que, modestamente, nos propomos ${ }^{1}$ (ALMEIDA, 1987, p. 1).

A seriedade da publicação deu-se pelo fato de não constar em suas páginas piadas ou outras discussões de cunho mais banais. O ideal da Revista A Mensageira fica bem claro, como já mencionado em seu primeiro número e por uma das suas ilustres colaboradoras, Júlia Lopes de Almeida:

Esta revista, dedicada ás mulheres, parece-me dever dirigir-se especialmente ás mulheres, incitando-as ao progresso, ao estudo, á reflexão, ao trabalho e a um ideal puro que as nobilite e as enriqueça, avolumando os seus dotes naturaes. Ensinará que, sendo o nosso, um povo pobre, as nossas aptidões podem e devem ser aproveitadas em variadas profissões remuneradas e que auxiliem a familia, sem detrimento do trabalho do homem (ALMEIDA, 1987, p. 4-5).

Dessa forma, percebe-se o quão profícua foi a revista, como exemplo de luta pelos direitos das mulheres, como também divulgadora da escrita feminina e incentivadora dos escritos que poderiam servir de exemplo para outras mulheres, como afirmou Presciliana Duarte de Almeida, na coluna Duas palavras, de 15 de outubro de 1897, no primeiro número do periódico:

Que as mais aptas, as de mérito incontestável, nos prestem o concurso de suas luzes e enriqueçam as nossas paginas com as suas producções admiráveis e bellas; que as que começam a manejar a penna, ensaiando o vôo altivo, procurem aqui um ponto de apoio, sem 'o qual nenhum talento se manifesta (ALMEIDA, 1987, p. 2). 
Rosana Kamita (2004) argumenta que a revista A Mensageira abriu espaço para se defender uma educação de qualidade às mulheres e em um segundo momento para que todas pudessem ter participação no mercado de trabalho "ideal partilhado por muitas feministas da época, que consideravam esse o caminho para a autonomia feminina econômica e intelectual" (KAMITA, 2004, p. 164). Para Jean François Sirinelli:

As revistas conferem uma estrutura ao campo intelectual por meio de forças antagônicas de adesão - pelas amizades que as submetem, as fidelidades que arrebanham e a influências que exercem - e de exclusão - pelas posições tomadas, os debates suscitados, e as cisões advindas (SIRINELLI, 2003, p. 249).

Por meio dos inúmeros contatos que a revista teve, a mulher brasileira pode ter escritos literários de grandes nomes como Júlia Lopes de Almeida, Maria Clara da Cunha, Revocata de Melo, Julieta de Melo e a própria Zalina Rolim. A literatura reflete a condição humana, dá voz àquelas que ficavam trancadas em seus lares. Por isso, a importância de A Mensageira, e o estudo desse tipo de material, trazendo à luz escritos de autoria feminina não consagrados pela historiografia literária.

\section{A EDUCADORA DO JARDIM DE INFÂNCIA}

Maria Zalina Rolim nasceu em 20 de julho de 1867, na cidade de Botucatu, São Paulo. Seu pai foi José Tolim de Oliveira Ayres e sua mãe Maria Cândida Amaral Gurgel. Vinda de uma família de excelentes condições financeiras, o acesso aos livros sempre fez parte da infância e da adolescência da poetisa. Começou a escrever aos treze anos, e conforme as informações de Rita de Cássia Silva Dionísio (2014, p. 339) “a sua inspiração teria sido Victor-Hugo e os escritores brasileiros Gonçalves Dias e Castro Alves". Diferentemente de outras mulheres escritoras, Zalina Rolim teve o apoio de seu pai. Antônio de Arruda Dantas (1983) aponta sobre isso:

Revelou-se, nesta atitude, o Dr. Rolim de Oliveira Ayres, pessoa de visão elevada e superior, pois, inclusive, a vocação literária, nas mulheres, à época, provocava ataques e, até, difamação. No entanto, ao-em-vez de dissuadir a filha para desistir da Poesia e das veleidades literárias, anima-a, e a dirige 
para orientação de pessoa experimentada na Arte e de sua particular confiança (DANTAS, 1983, p. 27).

Foi também colaboradora do periódico Correio Paulistano, de São Paulo que teve tiragem diária, com contos e alguns versos. Após isso, vários de seus escritos figuraram na imprensa da época. Seu primeiro livro foi $O$ coração, poesias, em 1893, recebido de maneira muito profícua pela crítica, conforme as informações de Maria Amélia de Toledo Piza (2008).

Além disso, outra forma não rara de divulgar seus escritos era a participação em saraus literários. E, assim, muitos poemas de Rolim ficaram conhecidos. De acordo com Valnikson Viana de Oliveira (2017, p. 52) nos salões que a poetisa conheceu grandes nomes, como Júlia Lopes de Almeida e sua prima Presciliana Duarte de Almeida. Zalina Rolim faleceu em 21 de junho de 1961, em São Paulo. Oliveira (2017, p. 63-64) ressalta que os versos da poetisa "permaneceram no imaginário infantil paulista, sendo recitados em homenagens públicas à autora, [...] recebendo reedições em coletâneas escolares até o final do século XX”.

Os escritos de Rolim à revista A Mensageira, segundo as informações de Oliveira (2017) foram inéditos, os quais vieram a figurar na coletânea Saudade, que ficou oculta até o fim de sua vida.

O trabalho apurado com a linguagem é visto desde os seus primeiros poemas. Iremos trazer à luz um poema do Livro das crianças. Reafirmamos que nosso intento é enfatizar a relevância da poetisa Zalina Rolim para a consolidação da poesia infantil brasileira e assinalar o refinamento vocabular de seus poemas. Devemos frisar que a poetisa é citada por Lajolo e Zilberman na obra Literatura infantil brasileira: histórias e histórias (1985) no capítulo destinado às produções brasileiras da Belle Époque. No entanto, temos apenas a menção ao nome de Rolim e ao Livro das crianças, de 1897.

Na obra Panorama histórico da literatura infantil/ juvenil (2010), Nelly Novaes Coelho também registra Zalina Rolim, nos estudos referentes às publicações do fim do Império no Brasil. Mais uma vez temos a alusão ao nome da poetisa, e ao Livro das crianças. Isso tudo evidencia o quão vultuosa é a pesquisa sobre Rolim e quanto a nossa historiografia carece de estudos sobre a autora. Sua poesia foi destinada ao público infantil, e antes de criticar o tom pedagógico dos escritos necessitamos entender o momento em que estavam sendo publicados seus poemas. 
O ano de 1890, data de uma significativa reforma no ensino público em São Paulo. É nesse período que surgiu o primeiro jardim de infância público no país, concebido aos holofotes dos ideais de Friedrich Froëbel, procurando respeitar os limites do aluno, conforme nos informa Oliveira (2017). É assim que veio à tona O livro das crianças, de Zalina Rolim. Oliveira (2017) assinala que:

[...] ]encomendou-se um livro de leitura à escritora, que continuou produzindo poesias para os primeiros anos de alfabetização, solicitadas por várias publicações especializadas em orientação pedagógica. Foi nessa época que ela escreveu a célebre composição "Cetim", sobre o gatinho de mesmo nome, publicada pela primeira vez na obra Leituras Moraes (1896), de Arnaldo de Oliveira Barreto, e tão disseminada por várias gerações de alunos paulistas. (OLIVEIRA, 2017, p. 56).

Diante desses fatos, O Livro das crianças foi publicado em 1897, pelo governo do estado de São Paulo, sendo distribuído nas escolas infantis. Vale lembrarmos aqui a citação de Coelho (2000) de que a literatura infantil foi produzida de acordo com o seu tempo. Por isso, a poesia teve esse caráter pedagógico e o livro de Rolim circulou nas escolas. Nas palavras de Piza (2008, p. 219), o talento de Rolim foi colocado "a serviço da construção de uma didática para a infância com a feição brasileira". Vejamos o poema "A primeira lição", o qual manteremos a grafia original:

\section{A PRIMEIRA LIÇÃO}

RAUL não sabe lêr;

É um traquinas, que vive toda a hora

Pela campina em fóra

A correr, a correr...

Desde pela manhã,

Salta do leito em fraldas de camisa,

E por tudo deslisa

Numa alegria sã.

Nada de livros, não;

Para ele a campina, os passarinhos,

Os assaltos aos ninhos,

A pesca ao ribeirão

E as corridas em pós

Dos bezerros e cabras e novilhas,...

Rasgando asperas trilhas,

Veloz, veloz, veloz!

Mas, um dia, elle viu 


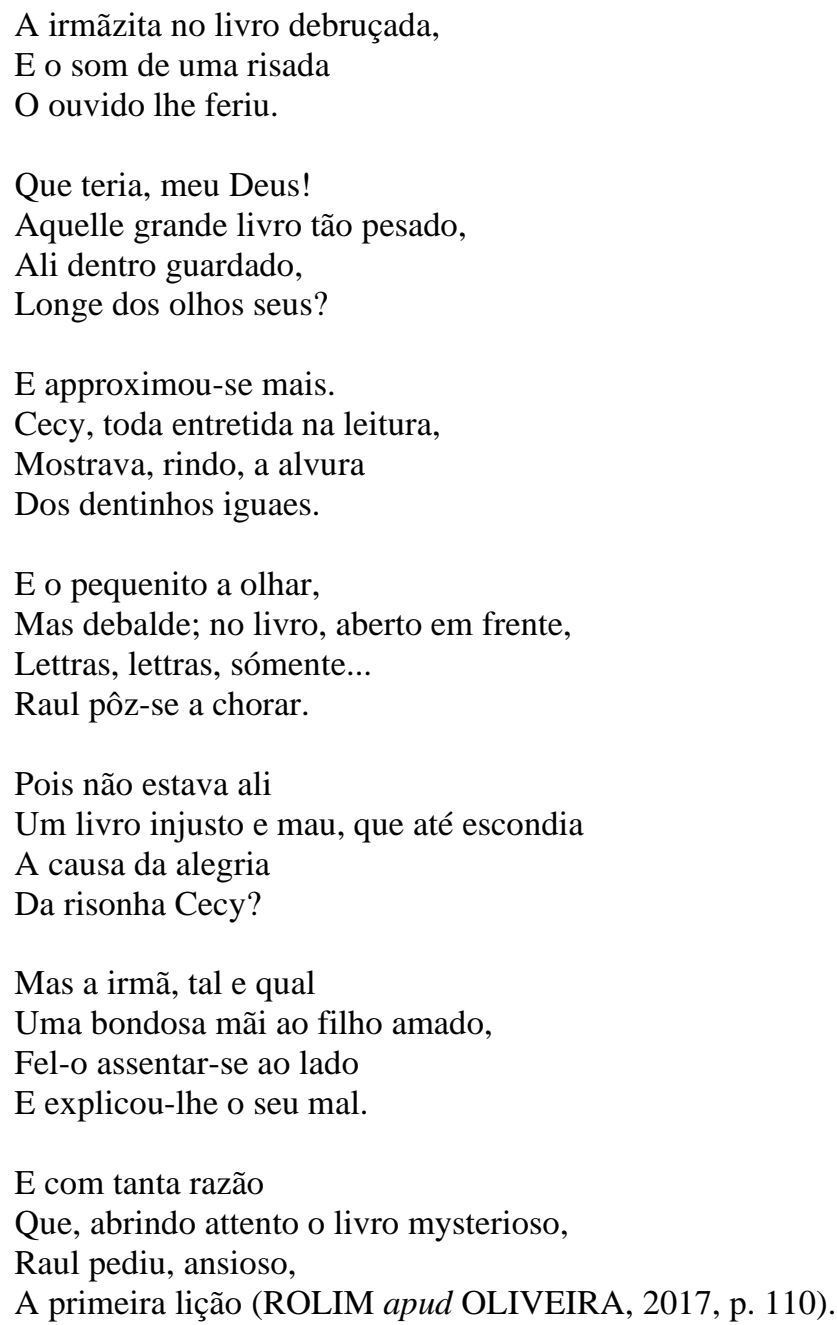

O poema é composto por onze quadras, todas com rimas ABBA. São rimas graves e agudas. É uma espécie de poema historieta, ou poema narrativo. Temos os feitos da infância do menino Raul e suas "peraltices". O ambiente rural predomina, típico da infância dos meninos da época. Existe uma descrição desse ambiente e a sensação de liberdade que as brincadeiras ao ar livre podem causar. Também é possível ver o descompromisso que a criança tem, como é bom ser criança e apenas brincar livre.

No entanto, algo muda no semblante de Raul. Ele vê sua irmã rindo ao ler um livro. Como assim? A diversão não está mais ligada ao brincar? Sim, ela está, porém, o livro também é responsável pela sensação de liberdade e pode proporcionar a diversão.

Há uma tentativa de associar ao livro o ensinamento, típico da época e o menino descobre uma nova forma de brincar: por meio da leitura do livro. Essa é a imagem que o poema pode vir a sugerir às crianças daquele período, que entraram em contato com a obra. É pertinente destacarmos que a publicação era ilustrada, todavia, não cabe nesse 
estudo fazer a análise das imagens que acompanhavam cada poema. Oliveira (2017) salienta sobre o poema:

\begin{abstract}
Os elementos de jogo vão sendo substituídos pelo interesse de aprender as primeiras letras, com o personagem sofrendo uma espécie de transformação moral no desenrolar da descrição: as quatro primeiras estrofes acompanham suas peraltices para, depois, o quinto estabelecer o conflito relacionado ao riso da irmã ao ler um grande livro, com os blocos subsequentes tratando de seu contato frustrante com o impresso e finalizando com sua compreensão de que aquela brochura também poderia proporcionar diversão. É interessante destacar que Rolim faz uso de uma situação envolvendo a leitura em sua percepção lúdica para indicar a importância do estudo e do livro para as crianças (OLIVEIRA, 2017, p. 110).
\end{abstract}

Mesmo marcada pelo aspecto pedagógico a poesia de Zalina Rolim ressalta as rimas, tão exploradas pela literatura infantil, ganham luz a fim de avultar a leveza das brincadeiras de crianças pelos campos, descobrindo e explorando lugares novos, que podem estar no livro, pois é nele que Raul vê sua irmã rindo. E, assim, solicita a ela sua primeira lição.

Isso tudo é apresentado no poema de modo natural, ou seja, a leitura não é imposta à criança. O menino fica curioso e ao mesmo tempo, bravo, por não entender como os sinais gráficos do livro causam o sentimento de alegria em sua irmã. Ele também quer participar desse novo universo.

Salientamos que embora o poema possa ser entendido com viés pedagógico traz à baila algo que a literatura infantil atual também persegue: despertar o interesse pela leitura no pequeno leitor. $\mathrm{O}$ menino do poema percebe que a brincadeira de ler também pode ser divertida, por isso quer aprender. Rolim teve a intenção de despertar os infantes para o prazer de ler. Dionísio (2014) sustenta a respeito do poema de Rolim:

\footnotetext{
A leitura do poema A primeira lição, de Zalina Rolim que, mesmo abordando um tema que nos parece paradoxal - o aprendizado da leitura em oposição às brincadeiras e jogos infantis - os aspectos estéticos do texto, as suas rimas, os versos curtos, a linguagem simples, as imagens sinestésicas, colaboram para a construção de um notável universo infantil - aspecto que poderia exemplificar a competência da autora e o alcance de sua produção à época em que foi escrita (DIONÍSIO, 2014, p. 344).
}

Os poemas de Rolim também estavam presentes nas suas contribuições à revista A Mensageira, desde o primeiro número de publicação da revista, em 1897. Também evidenciamos que a revista publicou muitos textos de crítica literária direcionados à 
obra $O$ livro das crianças. Na edição de número 9, de 15 de fevereiro de 1898, na seção "Carta do Rio", que foi assinada por Maria Clara da Cunha Santos, figurou uma crítica ao livro, deixando claro a beleza de seus poemas.

Essa mesma edição trouxe outra coluna intitulada "Impressões de leitura", que teve como conteúdo a crítica literária da época e foi assinada por Perpétua do Valle, pseudônimo da diretora da revista, Presciliana, e enfocou a publicação do Livro das crianças, de Rolim. Observemos um trecho:

[...] O Livro das Crianças deve merecer muito interesse da parte de nossas leitoras: é uma obra feita para nossos filhos e para nossos irmãos, e não póde deixar de despertar nossa sympathia. Ficará associado ás impressões que guardarmos de nossos adorados travessos e tanto basta para que seja um livro querido. Disse alguém que este trabalho "destinado ás crianças, póde ser lido com prazer pelos adultos", e affirmou uma verdade. A simplicidade, a correcção de linguagem e a delicadeza dos assumptos o tomam sobremodo agradavel e attrahente (VALLE, 1987, p. 138-139).

A transcrição de um excerto da crítica aponta para a consideração que Rolim teve à época da publicação de seu livro e a valorização de seus escritos. Como já afirmamos anteriormente, somente nesse número de A Mensageira, houve outra menção ao Livro das Crianças exaltando a qualidade dos versos da poetisa e o seu excelente trabalho com a linguagem. A crítica de Perpétua do Valle, inclusive, transcreveu o primeiro poema do livro que foi intitulado "Pouco a pouco". Não podemos esquecer que nesse mesmo número da revista, Rolim contribuiu com um poema.

Tudo isso comprova o quanto a poetisa do jardim de infância publicou durante o período em que viveu. Também pontuamos a importância do Livro das crianças e do reconhecimento que a sua publicação obteve, não somente na área da educação infantil, como também no meio literário. Fernanda Nunes dos Santos (2016) salienta que em vida Rolim foi homenageada inúmeras vezes sendo, inclusive, convidada para integrar a Academia Paulista de Letras, juntamente com Presciliana Duarte de Almeida e Francisca Júlia. As homenagens à poetisa vão desde escolas com o seu nome até bibliotecas e ruas.

\section{CONSIDERAÇÕES FINAIS}


Os poemas de Zalina Rolim, tanto publicados no Livro das crianças, como na revista A Mensageira, ou até mesmo em outros periódicos da época, denotam a beleza das imagens, e a riqueza vocabular proporciona ao leitor várias representações da infância, como brincadeiras, lugares, objetos. Maria da Glória Bordini (1991, p. 32) pondera que "para poder entender por que o poema significa mais do que o conjunto de seus signos é preciso ir além do nível verbal, entrando no campo das representações".

Com isso, nossa intenção é elucidar a importância dos escritos de Zalina Rolim para a poesia infantil brasileira. Mesmo que atrelada à ideia pedagógica, sua poesia foi marcante na época. E lida entre as crianças, agora ficou no esquecimento. Conforme Luís Camargo (2001, p. 88), a poesia infantil brasileira foi aparecendo "de braços dados com a escola, visando principalmente a aprendizagem da língua portuguesa”. E foi isso que aconteceu com Zalina Rolim. No entanto, não é motivo de desprestígio para sua escrita. Justamente, pelo fato de que anteriormente ao Livro das Crianças, a autora já havia feito outras publicações e tinha uma influência assídua em jornais e revistas da época, fato comprovado pelos seus escritos na revista A Mensageira e em outros periódicos. A poetisa do Jardim de Infância merece ser estudada e lida atualmente, pois exerce uma grande contribuição na consolidação da poesia infantil brasileira.

\section{Referências}

ALMEIDA, Júlia Lopes de. Entre amigas. In: ALMEIDA, Presciliana D. de (ed). A Mensageira: revista literária dedicada à mulher brasileira. Edição fac-similar. São Paulo: Imprensa Oficial do Estado: Secretaria de Estado da Cultura: São Paulo, 1987. p.4-5. v. I.

ALMEIDA, Presciliana Duarte de. Duas Palavras. In: ALMEIDA, Presciliana D. de (ed). A Mensageira: revista literária dedicada à mulher brasileira. Edição fac-similar. São Paulo: Imprensa Oficial do Estado: Secretaria de Estado da Cultura: São Paulo, 1987. p. 1-2. v. I.

ALMEIDA, Renato. "A literatura infantil". In: COUTINHO, Afrânio; COUTINHO, Eduardo de Faria (org.). A literatura no Brasil. 6.ed. São Paulo: Global, 2003. p. 206 225.

BORDINI, Maria da Glória. Poesia infantil. 2. ed. Porto Alegre: Ática, 1991.

CADEMARTORI, Lígia. O que é Literatura Infantil. 4. ed. São Paulo: Editora Brasiliense, 1987. 
CAMARGO, Luís. A poesia infantil no Brasil. In: Revista de Crítica Literaria Latinoamericana. Ano 27. n. 53. Lima - Hanover: 2001. pp. 87-94. Disponível em: http://www.jstor.org/stable/4531150. Acesso em: 08 fev. 2020.

COELHO, Nelly Novaes. Literatura infantil: teoria, análise, didática. 7. ed. rev. atual. São Paulo: Moderna, 2000.

COELHO, Nelly Novaes. Panorama histórico da literatura infantil/juvenil: das origens indo-europeias ao Brasil contemporâneo. 5.ed. rev. e atual. Barueri, SP: Amarilys, 2010.

COELHO, Nelly Novaes. O Conto de Fadas [livro eletrônico]: símbolos, mitos, arquétipos. São Paulo: Paulinas, 2012.

COSTA, Carlos. A revista no Brasil do século XIX: a história da formação das publicações, do leitor e da identidade do brasileiro. São Paulo: Alameda, 2012.

DANTAS, Antônio de Arruda. Zalina Rolim. São Paulo: Pannartz, 1983.

DIONÍSIO, Rita de Cássia Silva. "Infância e poesia em diálogo: 'a primeira lição' da literatura infanto-juvenil brasileira na perspectiva de Zalina Rolim". In: DUARTE, Constância Lima (et. al.). Arquivos femininos: literatura, valores, sentidos. Florianópolis: Ed. Mulheres, 2014. p. 337 - 347.

KAMITA, Rosana Cássia. Revista "A Mensageira”: alvorecer de uma nova era? Revista Estudos Feministas, Florianópolis, 2004, set./dez. p. 164-168. Disponível em: https://periodicos.ufsc.br/index.php/ref/article/view/S0104-026X2004000300018.

Acesso em: 16 de jul. 2019.

LAJOLO, Marisa; ZILBERMAN, Regina. Literatura infantil brasileira: história \& histórias. 2. ed. São Paulo: Ática, 1995.

OLIVEIRA, Valnikson Viana de. As raízes da poesia infantil de Zalina Rolim em Livro das crianças. 2017. 142 f. Dissertação (Mestrado) - Curso de Mestrado em Letras, Universidade Federal da Paraíba, João Pessoa, 2017. Disponível em: https://repositorio.ufpb.br/jspui/handle/123456789/11936. Acesso em: 12 fev. 2010.

PAIXÃO, Sylvia Perlingueiro. A fala-a-menos: poesia e imprensa feminina no final do século XIX e início do XX no Brasil. Dissertação de Mestrado. Rio de Janeiro: Pontifícia Universidade Católica do Rio de Janeiro, 1989, p. 54.

PIZA, Maria Amélia de Toledo. Zalina Rolim: poetisa e educadora. Itu/SP: Ottoni Editora, 2008.

SIRINELLI, Jean François. "Os intelectuais”. In: REMOND, R. (Org.). Por uma história política. Rio de Janeiro: Fundação Getúlio Vargas, 2003. p. 231-269. 
VALLE, Perpétua. Impressões de leitura. In: ALMEIDA, Presciliana D. de (ed). A Mensageira: revista literária dedicada à mulher brasileira. Edição fac-similar. São Paulo: Imprensa Oficial do Estado: Secretaria de Estado da Cultura: São Paulo, 1987. p.137-138. v. I.

ZILBERMAN, Regina. A literatura infantil na escola. 11. ed. rev., atual. e ampl. São Paulo: Global, 2003.

Recebido em: 15/01/2021

Aceito em: 27/06/2021

\footnotetext{
${ }^{1}$ As citações retiradas da revista $A$ Mensageira serão transcritas de acordo com a grafia original e foram retiradas da edição fac-similar publicada pela Secretaria do Estado da Cultura e Imprensa Oficial do Estado de São Paulo em 1987.
} 